\title{
A SIMULATION STUDY ON FIRE SERVICE INTERVENTION IN ROCK CAVERN WITH TILTED ACCESS TUNNEL
}

\author{
H.L. Tsang, N.K. Fong, W.K. Chow ${ }^{*}$ \\ Research Centre for Fire Engineering, Department of Building Services Engineering, The Hong Kong \\ Polytechnic University, Hong Kong, China
}

\begin{abstract}
The firefighting and rescue operations to be carried out by fire-fighters may be hampered by the complexity of the design layout of rock caverns especially at the initial stage of firefighting and leading the evacuees to escape. The problem may be escalated in case of only limited means of access leading to the interior of the rock cavern provided. The situation may be exacerbated in case that the access tunnel is designed as a descending tunnel instead of horizontal tunnel given that the large amount of smoke/flammable gases is accumulated at main entrance with larger tilted angle.

This paper aims at exploring the potential risks to be encountered by the fire-fighters when they arrive at scene of a fire involving a rock cavern with various types of access tunnel. Two types of design fire sizes in three types of access tunnel, e.g. horizontal, ascending, descending tunnels with different tilted angles to a cubic cavern space were studied by Computational Fluid Dynamics (CFD) simulations as well. Various correlations of key scientific criteria affecting fire service intervention in rock cavern were identified and discussed. Subsequently, according to the predicted results, recommendations in terms of mitigations on inherent risks of barrier to fire service intervention in rock caverns are proffered.
\end{abstract}

KEY WORDS: Fire service intervention, Rock cavern, Computational fluid dynamics (CFD) simulation, Tilted tunnel

\section{INTRODUCTION}

Rock caverns are usually designed as underground / confined spaces which may present the fire safety problems and inherent risks in terms of difficulties in evacuation, barrier to fire service intervention and insufficient ventilation. For the perspective of fire-fighting and rescue operations in rock cavern, barrier to fire service intervention should properly be addressed. The risks are intensified in case of rock caverns constructing with descending access tunnels given that the access tunnel is the sole means of access (MoA) leading to rock cavern and smoke as well as heat are usually spread and accumulated at the main entrance of the tunnel which creates challenges for the firefighters during fire service intervention. The situation may be exacerbated in case that the access tunnel is designed with a descending tunnel with larger tilted angle as the large amount of smoke/flammable gases is accumulated at main entrance in case of larger tilted angle of the tunnel [1].

In this connection, this paper aims at illustrating inherent risks of rock cavern with regard to the barrier to fire service intervention in case of fire in rock cavern and exploring the potential risks to be encountered by the fire-fighters when they arrive at scene of a fire involving a rock cavern with various types of access tunnel. Besides, two types of design fire sizes in three types of access tunnel, e.g. horizontal, ascending, descending tunnels with different tilted angles to a cubic cavern space were studied by Computational Fluid Dynamics (CFD) simulations as well. Various correlations of key scientific criteria affecting fire service 
intervention in rock cavern were identified and discussed. Subsequently, according to the predicted results, recommendations in terms of mitigations on inherent risks of barrier to fire service intervention in rock caverns are proffered.

\section{BARRIER TO FIRE SERVICE INTERVENTION}

The increase in complexity of layouts in caverns may adversely affect the efficiency of initial firefighting operations of first responders from the local fire brigade especially for the situation when only sole MoA is provided to deep rock caverns for fire service intervention. It is imperative to physically construct a designated MoA for firefighters and adopt an effective coordination between fire services and rescue team and the managerial staff at the rock cavern facility to mitigate such problem.

Due to the fact that local firefighting teams are not usually employed by the rock cavern facility, the operation of express fire suppression and guiding evacuation cannot be executed prior to the arrival of local fire brigade. The scale of fire at the initial stage can properly be controlled by automatic fire detection system and fire suppression system. Such provision is extremely crucial in case of descending access tunnel constructed in the rock cavern given that no alternative MoAs are provided to fireman at from the main entrance of such cavern. Smoke will be filled up at the upward part of the descending tunnel and larger amount of smoke will be flowed to the entrance as a result of a bigger tilted angle [1].

\section{NUMERICAL SIMULATIONS ON ENVIRONMENT TO BE ENCOUNTERED BY FIRE-FIGHTERS UPON ARRIVAL AT FIRE SCENE OF ROCK CAVERN}

Numerical simulations of fire scenarios in rock cavern in terms of different tilted angles of MoA tunnel leading to on a rock cavern model were carried out in order to analyze the environment to be faced by firefighters therein and the risks to be exposed by them upon arrival at the entrance of the rock cavern for handling the fire. The design of the cavern model and the relevant parameters for CFD simulations are depicted in the following paragraphs:

\subsection{Proposed Design of Rock Cavern for Simulations}

Taking the example of the fire safety design for rock cavern in Japan used as museum with high occupant load [2] and the proposed cavern design to be utilized as columbarium for local use [3], a modified design of rock cavern intended for accommodating high occupant load for future use in Hong Kong is recommended. Numerical simulations on fire safety design were conducted with regard to tenability limits in a $70 \mathrm{~m}-$ long access tunnel, which is used for connecting with the main entrance and the rock cavern as shown in Figure 1. The access tunnel is provided with a width of $7 \mathrm{~m}$ and a height of $6.5 \mathrm{~m}$, which is equivalent to the height of access tunnel in sewage treatment works constructed in rock cavern in Hong Kong [4]. Thus, the access tunnel is $70 \mathrm{~m}$ long, $7 \mathrm{~m}$ wide as well as $6.5 \mathrm{~m}$ high and the tunnel is served as a vehicular access for connecting between the main entrance and the interior of the rock cavern. Peripheral refuge tunnels of $3 \mathrm{~m}$ in width are also built adjacent to the access tunnel as separate routes. Thus, the dimension of the access tunnel with refuge tunnels is $70 \mathrm{~m}$ long, $15 \mathrm{~m}$ wide and $6.5 \mathrm{~m}$ high. The fire location is assumed at the end of tunnel leading to the cubic cavern space. The cavern design for simulations is illustrated in Figure 1. 


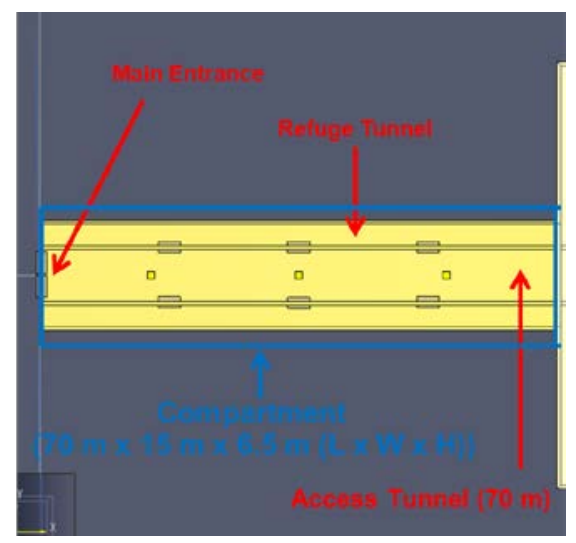

Fig. 1 Layout plans for the design of the proposed access tunnel.

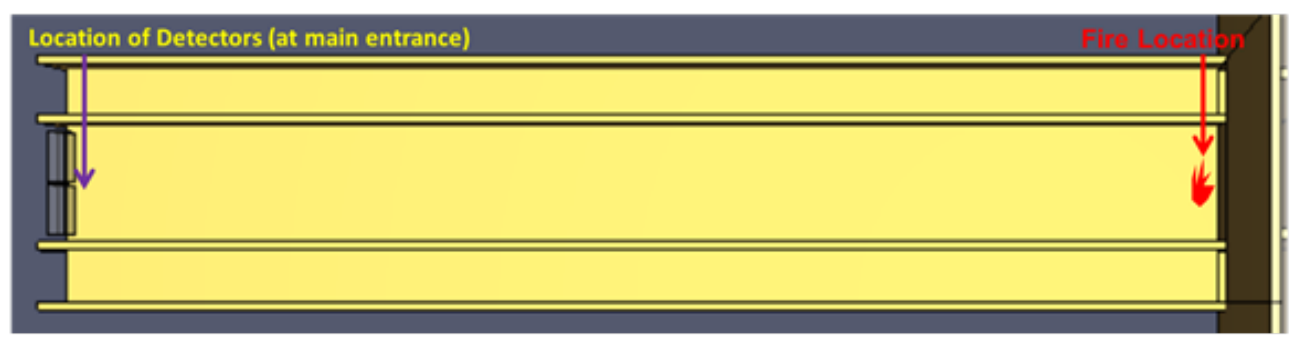

Fig. 2 Layout plans for the design of access tunnel leading to rock cavern.

\subsection{Fire and Detector Locations}

Design fire size is one of the paramount input parameters in performance-based design. One possible fire scenario the access tunnel leading to rock cavern space as shown in Figure 2 was simulated. Given that a design fire size of $2 \mathrm{MW}$ of a baggage fire is commonly adopted for railway station accommodating high occupant load in Hong Kong, an article made of polyurethane of $1 \mathrm{~m}^{2}$ with a heat release rate per unit area (HRRPUA) of 2,000 kW/m² is assumed to be ignited at the fire location. Thus, a design fire size of $2 \mathrm{MW}$ is selected for the simulations. Meanwhile, a bigger design fire size of $5 \mathrm{MW}$ for a vehicle fire at access tunnel is also used for simulations for further comparison. In this connection, two types of design fire sizes of 2 MW and 5 MW are assumed as the design fire sizes. Meanwhile, a set of devices including thermocouples and CO concentration detectors were set up at the main entrance of the tunnel. In order to measure the CO concentration and temperature vertically as from the ground to the ceiling, a total of 12 sets of devices were set up at heights of $0.5 \mathrm{~m}$ to $6 \mathrm{~m}$ above finished floor level (AFFL) with $0.5 \mathrm{~m}$ spacing vertically (i.e. at heights of $0.5 \mathrm{~m}, 1 \mathrm{~m}, 1.5 \mathrm{~m}, 2 \mathrm{~m}, 2.5 \mathrm{~m}, 3 \mathrm{~m}, 3.5 \mathrm{~m}, 4 \mathrm{~m}, 4.5 \mathrm{~m}, 5 \mathrm{~m}, 5.5 \mathrm{~m}$ and $6 \mathrm{~m}$ AFFL). Two design fire sizes of $5 \mathrm{MW}$ and $2 \mathrm{MW}$ are assumed at the access tunnel for a vehicle fire and baggage fire respectively at the end of tunnel leading to rock cavern space as illustrated in Figure 2. At the access tunnel, no smoke extraction system is provided to the tunnel to assume the worst case scenarios of the breakdown/maintenance of the smoke extraction/exhaust system in the tunnel.

Thus, the fire and smoke spread to the main entrance along the various types of tilted tunnels were simulated. Seven types of tunnel gradient including horizontal tunnel, descending tunnels with the tilted angles of $+3^{\circ}$, $+6^{\circ}$ and $+9^{\circ}$ as well as ascending tunnels with the inclined angles of $-3^{\circ},-6^{\circ}$ and $-9^{\circ}$ were simulated by CFD package Fire Dynamics Simulator (FDS). FDS is a CFD model of fire-driven fluid flow and developed by the National Institute of Standards and Technology (NIST) in USA. A form of the Navier-Stokes equations appropriate for low-speed, thermally-driven flow with an emphasis on smoke and heat transport from fires is solved numerically by FDS. The numerical algorithm and formulation of the equations are discussed in the FDS Technical Reference Guide [5]. The examples of the scenarios of the tilted tunnels are illustrated in Figures 3 to 5. 

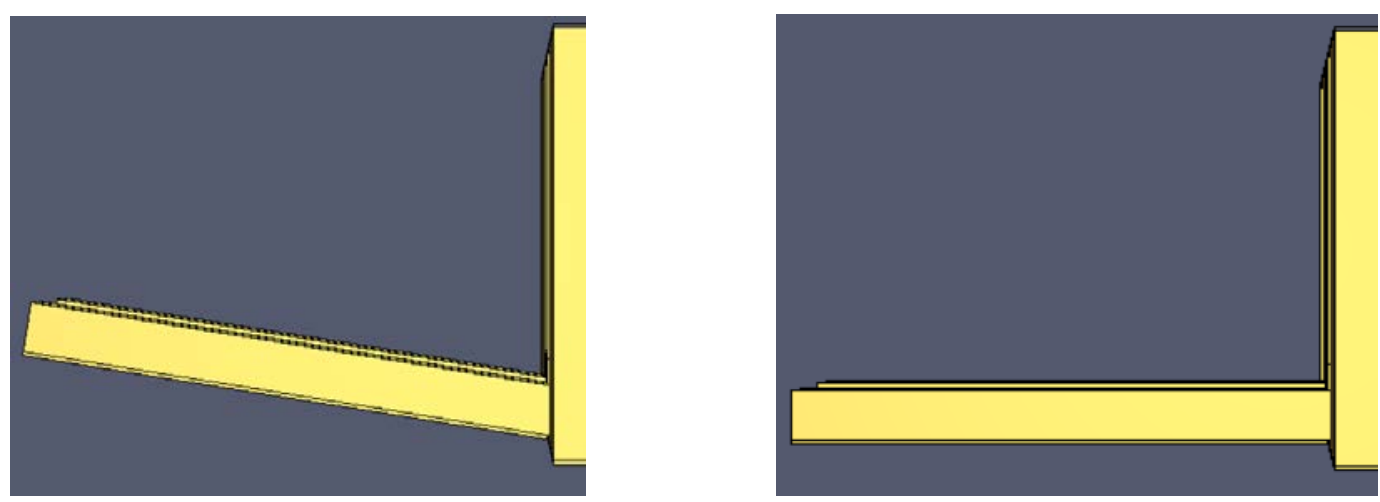

Fig. 3 Cavern with descending tunnel(Tilted angle $\left.+9^{\circ}\right)$. Fig. 4 Cavern with horizontal tunnel(Tilted angle $0^{\circ}$ ).

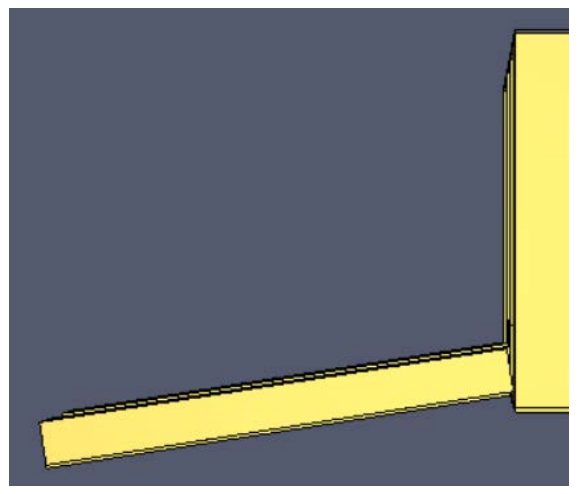

Fig. 5 Cavern with ascending tunnel(Tilted angle $-9^{\circ}$ ).

\subsection{Parameters of Numerical Simulation}

A total of 14 scenarios with 2 kinds of design fire sizes and 7 types of tunnel gradient were simulated. The scenarios of fire and smoke spread at the time of $300 \mathrm{~s}$ were simulated with reference to the graded response time of Hong Kong Fire Services Department (FSD). The graded response time is defined as the total amount of time allowed for the fire-fighters in Hong Kong to arrive at the scene of fire after the Fire Services Communications Centre (FSCC) of FSD received a fire call from the general public. Five types of graded response time ranging from 6 to 23 minutes [6] were designated by FSD taking into account the fire risks, building density as well as other factors across the territory. For normal urban areas, the graded response time is 6 minutes. In such response time of 6 minutes, preparation time of one minute should be reserved for deploying resources and establishing fire-fighting and rescue operation after arrival at scene. In general, it is assumed that fire-fighters will arrive at the scene within 5 minutes (300 s) after the FSCC received a fire call from the general public. In this connection, the time for simulations at $300 \mathrm{~s}$ is taken to reflect the risks to be encountered by fire-fighters upon arrival at fire scene. As stipulated in Code of Practice for Fire Safety for Buildings [7], the tenability limits are smoke clear height of $2 \mathrm{~m}$, smoke temperature should not exceed 60 ${ }^{\circ} \mathrm{C}$ and toxicity (CO concentration) should not exceed 1,000 ppm.

The simulations of phenomena of fire and smoke in the proposed cavern design are carried by CFD package Fire Dynamics Simulator 6.6.0, which was developed by NIST. Simulations were conducted by a laptop computer with multi-cores (4 cores) and multi-threads (8 threads) processor (CPU - Intel i7-8550U) with base frequency of $1.8 \mathrm{GHz}$ and max turbo frequency of $4 \mathrm{GHz}$. Meanwhile, the computer also incorporates a display card of NVIDIA ${ }^{\circledR}$ GeForce MX150 with GPU (Graphics Processing Unit) Boost 3.0, RAM of 16 GB and SSD hard drive of 256 GB. Three-dimensional Cartesian coordinate $\mathrm{x}, \mathrm{y}, \mathrm{z}$ was adopted on the gird system and computing domain for the compartment was set to be $70 \mathrm{~m}(\mathrm{~L}) \times 15 \mathrm{~m}(\mathrm{~W}) \times 50.5 \mathrm{~m}(\mathrm{H})$. Given the large compartment comprising a long tunnel of $70 \mathrm{~m}$, the grids are uniformly distributed of size $0.5 \mathrm{~m}$. 


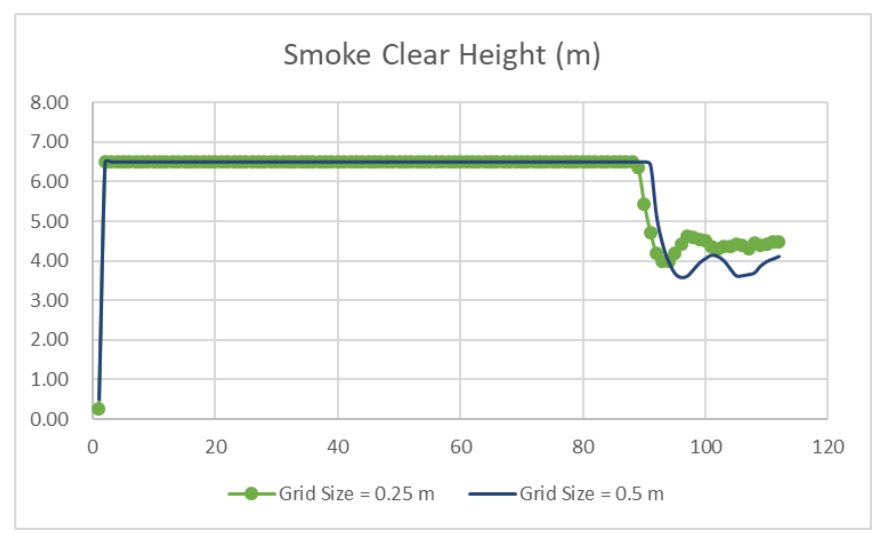

Fig. 6 Simulated results (grid dependency analysis) of smoke clear height in horizontal tunnel (5 MW fire)

The whole domain geometry was divided up to 424,200 parts and the grid system of the compartment was set as 140 by 30 by 101 along x-, y- and z-directions. The convergence of the predicted results was determined by means of the adoption of Courant-Friedrichs-Lewy (CFL) criterion. The corresponding CFL number would be computed in every time step. In addition, the time step would be adjusted in case that the maximum value of the CFL number is less than 1.0. With a view to allowing free fluid flow from inside to outside of the computation region, free boundary is used as interfacing region between the external environment as well as the computation region. Meanwhile a mesh independence study using the grid size of $0.25 \mathrm{~m}$ for a case of horizontal tunnel with $5 \mathrm{MW}$ fire was conducted. As the comparison of the results between the grid size of $0.5 \mathrm{~m}$ and $0.25 \mathrm{~m}$ are similar as shown in Figure 6, it is considered that the gird systems of other fire scenarios using grid size of $0.5 \mathrm{~m}$ are adequate to predict the accurate results from the numerical simulations.

\section{RESULTS AND DISCUSSION}

\subsection{Results of Simulations on Different Angles of Tilted Tunnels}

4.1.1 Horizontal Tunnel (5 MW Fire)., The results of CFD simulations as shown in Figure 7 revealed that the smoke clear height (SCH) can be maintained at $3.8 \mathrm{~m}$ AFFL at the main entrance of horizontal access tunnel at $300 \mathrm{~s}$ after an ignition of a $5 \mathrm{MW}$ fire. In accordance with the simulation results at 300s from the detector situated at $4 \mathrm{~m}$ AFFL, the temperature of $67{ }^{\circ} \mathrm{C}$ was predicated in Figure 8 whilst CO concentration of 250 ppm $(0.00025 \mathrm{~mol} / \mathrm{mol})$ was predicated in Figure 9.
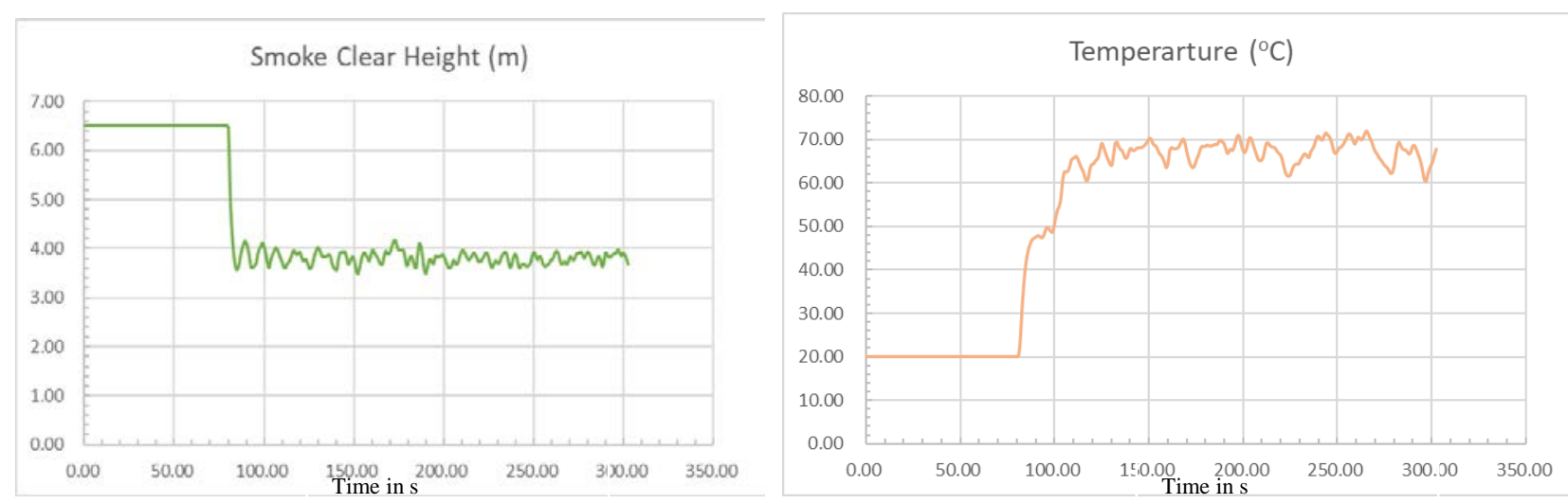

Fig. 7 Predicted SCH in horizontal tunnel(5 MW). Fig. 8 Predicted temperature in horizontal tunnel(5 MW). 


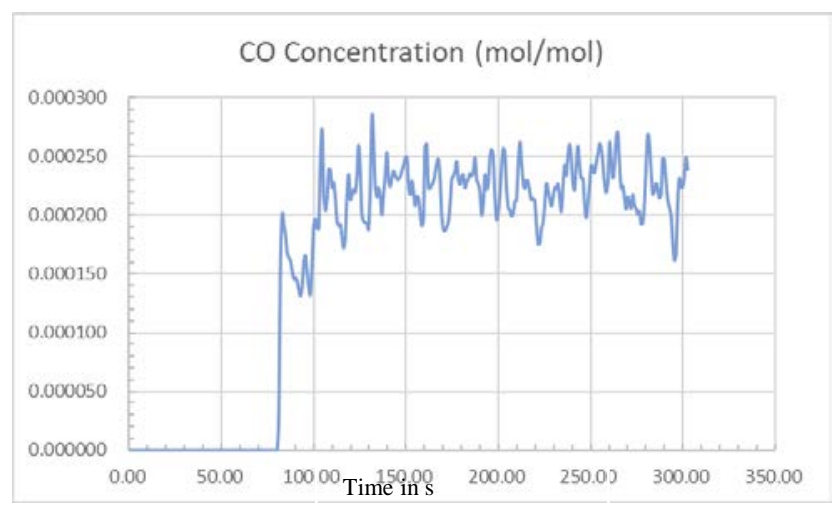

Fig. 9 Predicted CO concentration in horizontal tunnel (5 MW fire).
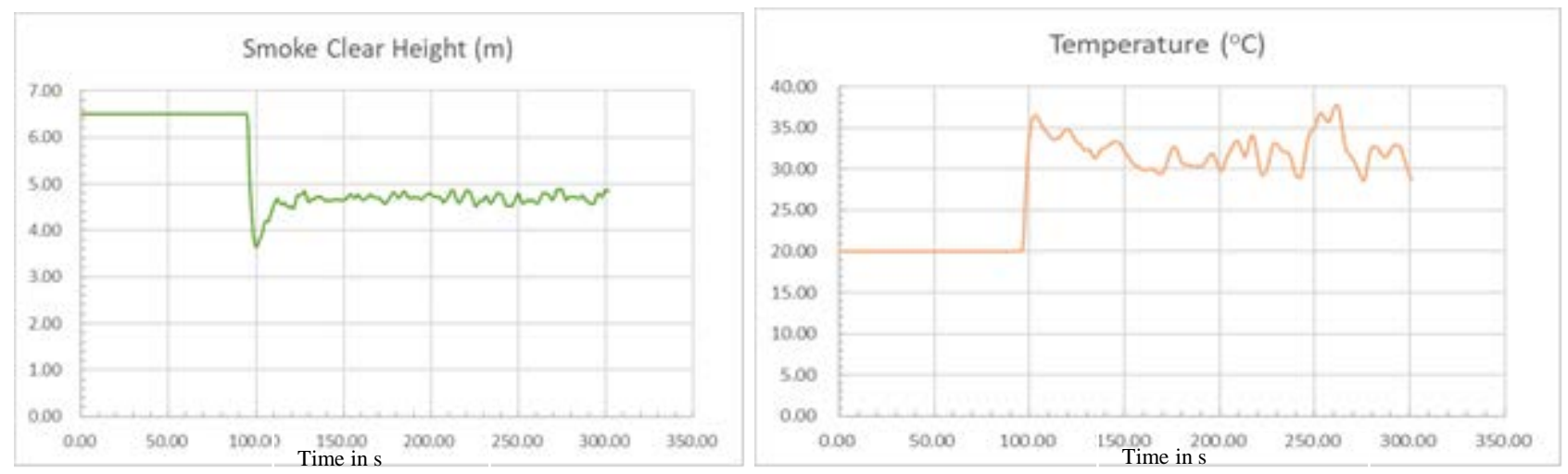

Fig. 10 Predicted SCH in horizontal tunnel(2MW) Fig. 11 Predicted temperature in horizontal tunnel(2MW).

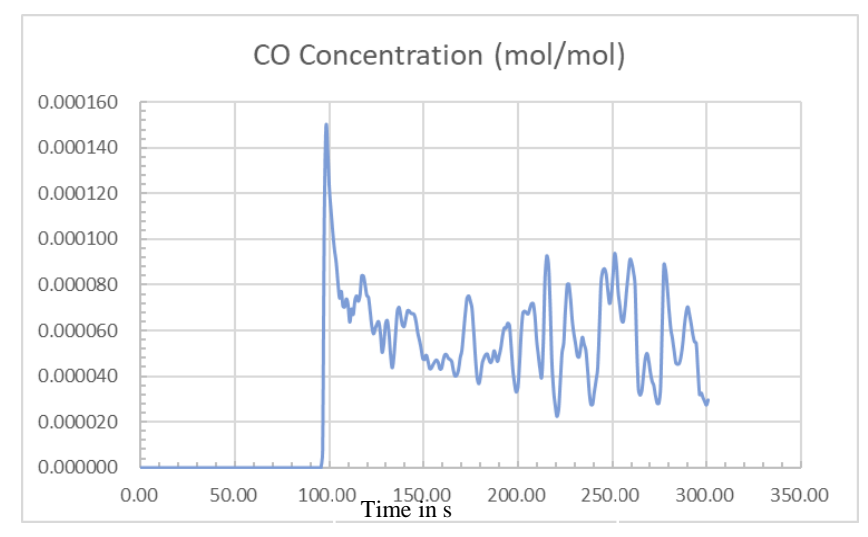

Fig. 12 Predicted CO concentration in horizontal tunnel (2 MW).

4.1.2 Horizontal Tunnel ( 2 MW fire). The results of CFD simulations as shown in Figure 10 revealed that the smoke clear height can be maintained at $4.84 \mathrm{~m}$ AFFL at the main entrance of horizontal access tunnel at 300 $\mathrm{s}$ after an ignition of a $2 \mathrm{MW}$ fire. In accordance with the simulation results at 300s from the detector situated at $4 \mathrm{~m}$ AFFL, the temperature of $27.5^{\circ} \mathrm{C}$ was predicated in Figure 11 whilst CO concentration of 26 ppm $(0.000026 \mathrm{~mol} / \mathrm{mol})$ was predicated in Figure 12 . The risks to be encountered by fire-fighters are less severe given that more tenable environment can be maintained in the simulation of a 2 MW fire comparing with the predicted results of a 5 MW fire as illustrated in paragraph 4.1.1.

Meanwhile, the predicted results of all scenarios are tabulated in Tables 1 and 2. 
Table 1 Comparison between the simulated results at main entrance of access tunnel with various tilted angles at $\mathrm{t}=300 \mathrm{~s}$ for a $5 \mathrm{MW}$ fire.

\begin{tabular}{l|c|c|c}
\hline & Smoke Clear Height $(\mathrm{m})$ & Temperature $\left({ }^{\circ} \mathrm{C}\right)$ & CO Concentration (ppm) \\
\hline $\begin{array}{l}\text { Tilted angle at }+9^{\circ} \\
\text { (descending tunnel) }\end{array}$ & 2.8 & 81 & 365 \\
$\begin{array}{l}\text { Tilted angle at }+6^{\circ} \\
\text { (descending tunnel) }\end{array}$ & 3.1 & 73 & 320 \\
$\begin{array}{l}\text { Tilted angle at }+3^{\circ} \\
\text { (descending tunnel) }\end{array}$ & 3.6 & 71 & 278 \\
$\begin{array}{l}\text { Tilted angle at } 0^{\circ} \\
\text { (horizontal tunnel) }\end{array}$ & 3.8 & 67 & 250 \\
$\begin{array}{l}\text { Tilted angle at }-3^{\circ} \\
\text { (ascending tunnel) }\end{array}$ & 4.84 & 21.32 & 8 \\
$\begin{array}{l}\text { Tilted angle at }-6^{\circ} \\
\text { (ascending tunnel) }\end{array}$ & 5.34 & 20.4 & 7 \\
$\begin{array}{l}\text { Tilted angle at }-9^{\circ} \\
\text { (ascending tunnel) }\end{array}$ & 6.5 & 20.03 & 5 \\
\hline
\end{tabular}

Table 2 Comparison between the simulated results at main entrance of access tunnel with various tilted angles at $\mathrm{t}=300 \mathrm{~s}$ for a 2 MW fire.

\begin{tabular}{l|c|c|c}
\hline & Smoke Clear Height (m) & Temperature $\left({ }^{\circ} \mathrm{C}\right)$ & CO Concentration (ppm) \\
\hline $\begin{array}{l}\text { Tilted angle at }+9^{\circ} \\
\text { (descending tunnel) }\end{array}$ & 3.1 & 37.8 & 118 \\
$\begin{array}{l}\text { Tilted angle at }+6^{\circ} \\
\text { (descending tunnel) }\end{array}$ & 3.4 & 33 & 98 \\
$\begin{array}{l}\text { Tilted angle at }+3^{\circ} \\
\text { (descending tunnel) }\end{array}$ & 3.75 & 28 & 95 \\
$\begin{array}{l}\text { Tilted angle at } 0^{\circ} \\
\text { (horizontal tunnel) }\end{array}$ & 4.84 & 27.5 & 26 \\
$\begin{array}{l}\text { Tilted angle at }-3^{\circ} \\
\text { (ascending tunnel) }\end{array}$ & 5.04 & 20.59 & 7 \\
$\begin{array}{l}\text { Tilted angle at }-6^{\circ} \\
\text { (ascending tunnel) }\end{array}$ & 6.5 & 20.02 & 5 \\
$\begin{array}{l}\text { Tilted angle at }-9^{\circ} \\
\text { (ascending tunnel) }\end{array}$ & 6.5 & 20.02 & 0 \\
\hline
\end{tabular}

\subsection{Discussions on Impacts of Tilted Angles and Design Fires}

In the light of the results of numerical simulations as depicted in paragraphs 4.1.1 to 4.1.2 and the predicted results illustrated in Tables 1 and Table 2, the design of tilted angle of the access tunnel is highly related to the rate of fire/smoke spread along such tunnel. The results indicated that faster fire/smoke spread is generated by larger titled angle of the tunnel. Similar to the experimental results conducted by Chow et al. [1], in case of large tilted angle of the tunnel, faster spread of smoke plume would be resulted. It is also shown that the rate of fire/smoke spread is highly related to design fire size in the light of the results from the numerical simulations by CFD package FDS. The results from CFD simulations indicated that the higher rate of fire/smoke spread along the tunnel may be generated by the larger design fire size.

For instance, the smoke clear height at the main entrance of the horizontal access tunnel at $300 \mathrm{~s}$ will descend to $3.8 \mathrm{~m}$ for a $5 \mathrm{MW}$ fire while the smoke clear height only descends to $4.84 \mathrm{~m}$ for a $2 \mathrm{MW}$ fire. 
Furthermore, the temperature at $4 \mathrm{~m}$ AFFL at the main entrance of the horizontal access tunnel at $300 \mathrm{~s}$ increase to $67{ }^{\circ} \mathrm{C}$ for a $5 \mathrm{MW}$ fire whilst the temperature only raised to $27.5^{\circ} \mathrm{C}$ in case of $2 \mathrm{MW}$ fire. As a result, it is indicated that the larger the fire size, the faster the fire spread may be generated. Moreover, the temperature and CO concentration is predicted to be higher at tunnel entrance with the larger angle of tilted tunne1 and smoke clear height at the tunnel entrance may descend to its tenability limit faster when the tilted angle is larger.

The results also indicated that the shorter time for the tenability criteria to reach the relevant limits in case of the larger the tilted angle of the descending tunnel. The phenomena also illustrated that the fire-fighters may encounter higher risk of exposure to the untenable conditions in case of the larger tilted angle of a descending tunnel. Furthermore, the firemen may have shorter time for preparation for access to the rock cavern due to faster accumulation of heat and smoke at the entrance.

\section{RECOMMENDATIONS ON MITIGATIONS ON INHERENT RISKS OF BARRIER TO FIRE SERVICE INTERVENTION IN ROCK CAVERNS}

\subsection{Enhancements on Design of Rock Cavern}

With a view to mitigating the risk to be exposed by the fireman for fire service intervention due to the tilted access tunnel of rock caverns, it is proposed that a dedicated means of access leading to the cavern such as refuge tunnels with pressurization system should be provided to ensure the safety of the personnel responsible for the fire service intervention. Further, with a view to mitigating the problem of faster rate of smoke along the access tunnel, such tunnel should be designed as horizontal instead of a tunnel with tilted angle. In case of design features due to site constricts in constructing a horizontal tunnel, the tilted angle should be designed as minimal as possible in order to address the problem of such tunnel design. Moreover, the design fire size should be carefully adopted in fire safety strategy of a rock cavern and adequate fire safety provisions (e.g. smoke extraction system) should be installed to address the problem of faster fire/smoke spread due to larger design fire size.

\subsection{Implementation of Effective Firefighting and Rescue Strategy for Rock Cavern}

Implementation of effective firefighting and rescue strategy is recommended for tackling fire in rock cavern especially for the descending access tunnel. In general, firefighting and rescue strategy in handling fire or other calamity in rock caverns may incorporate the key considerations as follows [8]:

- Modius operandi for activation of alarm and other essential equipment

- $\quad$ Promptness and efficiency of initial response

- Efficiency of inter-departmental liaison

- Internal communications as well as command and control

- Preparation of preliminary reconnaissance

- Procedures of fire service intervention

- Arrangements of casualty handling

- Deployment of equipment and personal protective equipment utilized at scene

- $\quad$ Requirement of special equipment

- Inter-departmental planning and coordination

Meanwhile, the specific strategies for handling incidents for different uses of rock caverns such as storage facilities (magazine) and sewage treatment works are illustrated as follows:

5.2.1 Rock cavern for storage facilities. The rock caverns utilized for storage facilities including magazine are normally located in structures converted from their originally uses. The various types of storage include arching, wine storage, explosives storage, etc. Thus, the complicated design of the facility can create 
unfamiliar and unfavourable environment for personnel responsible for firefighting and rescue operations. The relevant considerations on the operational strategies for the cavern storage facilities are illustrated as follows [8]:

- Liaison between the on-site personnel and recognition of status of the activation of fire service installations.

- Assessing the progress of evacuation of staff and workers therein.

- Identification of possible escalation of the incident and formulation of appropriate plan for fire service invention.

- Prevention of spread of fire until the establishment of adequate resources.

5.2.2 Rock Caverns for Sewage Treatment Works. Sewage treatment works/plants is usually relocated to inside rock cavern due to its environmental benefits in restricting the release the poisonous and odour gases to the neighbourhood [8]. Special considerations on handling incidents sewage treatment works/plants in rock caverns are depicted as follows [8]:

- Seeking experts' advice from the on-site staff for mitigating the corresponding risks and hazards in the treatment plants

- Implementation of suitable measures for controlling and protecting fire-fighters from the potential hazards

- Considerations on measures for mitigation of pollution by implementing off-site arrangements

\subsection{Provision of Adequate Equipment for Fire Service Intervention}

Necessary fire-fighting equipment provided on-site and specialized for fire service intervention in rock caverns should be proffered by the owner or the management of cavern facilities with a view to assisting firefighters during fire service intervention. Management of the rock cavern facilities should provide on-site equipment including breathing apparatus (BA) and specialized equipment for ventilation. The types of BA to be provided should be of long-duration type so as to provide longer working time of BA for firefighters. The utilization of closed-circuit breathing apparatus (CCBA) should be taken into account so that approximate working hours of 4 hours can be achieved.

To ensure safety of firefighters during fire service intervention, the relevant requirements/ standard in Singapore [9] and US [10] required the provision of firefighting equipment including hose as well as breathing apparatus to be provided on site. Such provision is suggested to be added into the next revision of the Hong Kong Guide [11]. Other provisions as stipulated in Singapore Requirements [8] such as formation of on-site emergency team for tackling the fire at the initial stage and electrically-driven buggies with stretcher to be provided in cavern should be provided at rock cavern facilities. It is also recommended that each cavern should be designed with a tailor-made fire safety strategy for mitigating the specified inherent risks due to its design features. In addition, with the establishment of on-site fire and rescue team to be deployed in the rock cavern, the efficiency of the firefighting operation can be enhanced by rapid intervention.

\section{CONCLUSIONS}

Inherent risk of rock cavern with regard to barrier to fire service intervention in case of fire in rock cavern was depicted the potential risks to be faced by the fire-fighters upon arrival at the main entrance of different types of access tunnels leading to a rock cavern were explored. Moreover, two types of design fire sizes in three types of access tunnel, e.g. horizontal, ascending, descending tunnels with different tilted angles to a rock cavern space were studied by numerical simulations as well. Various correlations of key scientific criteria affecting fire service intervention in rock cavern were identified and discussed. 
The predicted results from CFD simulations revealed that the shorter time for the tenability criteria to reach the relevant limits in case of the larger tilted angle of the descending tunnel. The phenomena illustrated that the fire-fighters may encounter higher risk of exposure to the untenable conditions in case of the larger tilted angle of a descending tunnel. The firemen may have shorter time for preparation for the access to the rock cavern due to faster accumulation of heat and smoke at the entrance. In this connection, such additional risk should be taken into account in designing a fire safety strategy to ensure the safety of firefighters in case of a tilted access tunnel constructed in the cavern. Mitigations on inherent risks of barrier to fire service intervention in rock caverns such as enhancements on design of rock cavern, implementation of effective firefighting and rescue strategy for rock cavern as well as provision of adequate equipment for fire service intervention were also recommended. The identified correlations of key scientific criteria and the recommendations can be served as good references for designing future rock cavern in Hong Kong intended for housing high occupant load [12].

\section{ACKNOWLEDGMENT}

The work described in this paper was supported by a grant from PolyU (UGC) for the project "A scalemodelling study on ventilation-limited cavern fires” (PolyU 152111/17E) with account number G-YBTD.

\section{REFERENCES}

[1] Chow, W.K., Wong K.Y. and Chung, W.Y., "Longitudinal ventilation for smoke control in a tilted tunnel by scale modeling," Tunneling Underground Space Technol., 25(2), pp. 122-128 (2010).

[2] Yoshimura, M., Seta S., Shioda, M. and Chikashisa, H., "Acoustics Characteristics in an Underground Hemisphere Exhibition Space of Takayama Festive Art Museum,” Proc. of 8th International Underground Space Conference, Xi’An, China (1999).

[3] Luo, M., Fire Safety of Cavern. PPT slides presented in Joint Seminar by HKIE Civil and Fire Division - When Civil Engineers meet Fire Engineers - The Fire Safety and Practices in Civil and Infrastructure Projects (2013).

[4] Ip, K.P. and Sam, K.P., "Sewage Treatment Works in Cavern - Hong Kong Experience," Proc. of the HKIE-HKIP Joint Conference on Planning and Development of Underground Space, pp. 209-213 (2011).

[5] McGrattan, K., Hostikka, S., McDermott, R., Floyd, J., Weinschenk, C., Overholt, K., Fire Dynamics Simulator (Version 6) User's Guide, NIST Special Publication 1019-6, National Institute of Standards and Technology, US Department of Commerce, USA, November (2013).

[6] Government of the Hong Kong Special Administrative Region, Hong Kong Fact Sheets (2018).

[7] Buildings Department, Code of Practice for Fire Safety for Buildings 2011. Government of the Hong Kong Special Administrative Region (2011).

[8] Department for Communities \& Local Government, Fire and Rescue Service Operational Guidance - Incidents in Tunnels and Underground Structures, The Stationery Office, London, England (2012).

[9] SCDF, Amendments to the Fire Code - Fire Safety Requirements for Mega Underground Developments. Fire Safety and Shelter Development of Singapore Civil Defence Force (2012).

[10] National Fire Protection Association, NFPA 520 Standard on Subterranean Spaces 2016 Edition. NFPA, USA (2016).

[11] Building Authority and Fire Services Department, Guide to Fire Safety Design for Caverns. Government of Hong Kong (1994).

[12] Tam, T.K., Tsang, H.L., Lui, G.C.H, Fong, N.K., Chow, W.K., "Fire safety strategies for existing rock caverns in Hong Kong,” Tunnelling Underground Space Technol., 43, pp. 78-87 (2014).

TFEC-2020-31768-TsangHL 